\title{
What Arteries are Affected in Familial Hypercholesterolemia?
}

\author{
Mariko Harada-Shiba
}

Department of Molecular Innovation in Lipidology, National Cerebral and Cardiovascular Center Research Institute, Osaka, Japan

\section{See article vol. 26: 1045-1053}

Atherosclerosis is known to occur in various arteries and is the cause of many arterial diseases. The major risk factors for atherosclerosis are high low-density lipoprotein cholesterol (LDL-C) levels, low highdensity lipoprotein cholesterol (HDL-C) levels, high lipoprotein (a) ( $\mathrm{Lp}(\mathrm{a})$ ) levels, smoking, hypertension, diabetes mellitus, and so on. Familial hypercholesterolemia $(\mathrm{FH})$ is a genetic disease that is characterized by high LDL-C levels since birth ${ }^{1,2}$. In order to assess the pathogenic role of high LDL-C levels in atherosclerosis, patients with $\mathrm{FH}$ and LDL receptor knock out animals are an adequate model and have been used by researchers. Coronary artery disease (CAD) has been known to be a major manifestation of $\mathrm{FH}$ due to premature atherosclerosis in the coronary arteries. On the other hand, there have been controversial reports on the prevalence of cerebrovascular disease (CVD) and peripheral artery disease (PAD) in FH.

In order to assess the incidence of atherosclerotic cardiovascular disease, we need to consider the era in which a particular study was performed, that is, the prestatin or posstatin era. Kaste et al. ${ }^{3)}$ reported that the risk of CVD in patients with $\mathrm{FH}$ is 20 times higher; furthermore, Gange et al. ${ }^{4)}$ reported very high risk of CVD in patients with FH. In a meta-analysis, in the prestatin era, $\mathrm{FH}$ patients showed a higher risk for stroke compared with the general population (odds ratio $=7.6585)^{5}$. Both the studies were performed in the prestatin era. Mohrschladt et al. (5) $^{\text {and Jansen et }}$ al. ${ }^{6}$ reported a lower incidence of CVD in patients with $\mathrm{FH}$ than in control subjects. A meta-analysis also showed low incidence of CVD in patients with $\mathrm{FH}$ who were treated with statins ${ }^{5}$. These results suggest that patients with $\mathrm{FH}$ have a high prevalence of CVD, which can be prevented using statins.

In the present paper, Todate et al. evaluated the prevalence of small vessel disease in 28 patients with
$\mathrm{FH}$ and 35 healthy controls by using high-resolution brain magnetic resonance imaging $(\mathrm{MRI})^{6}$. Ultrahigh-field 7.0 Tesla MRI provides an increased signalto-noise ratio of the inflow signal at high spatial resolution, enabling the investigation of microvasculature characteristics. Patients with FH showed a significantly higher prevalence of periventricular hyperintensity than the controls. The major intracranial arteries and the signal intensity of lenticulostriate arteries were identical. The results of the present paper show that high LDL-C levels may affect small arteries. The low incidence of statin use in this study may have contributed to the positive results.

Atherosclerosis is a systemic and diffuse vascular disease. Therefore, it simultaneously affects various arteries. Carotid, peripheral, and coronary arteries share common risk factors such as diabetes mellitus, hypertension, aging, low HDL-C levels, and high triglyceride levels ${ }^{7}$. However, some risk factors have different impacts on different arteries. There have been several reports about the high impact of LDL-C levels on the prevalence of CAD. On the other hand, hypertension may be a more important risk factor for CVD, and smoking and diabetes mellitus may be more important risk factors for $\mathrm{PAD}^{8)}$.

It is worth mentioning that the characteristics of the increased lipoproteins may have some effect on the affected arteries. Dysbetalipoproteinemia (Fredrickson type III hyperlipidemia) is an atherogenic genetic disease and is associated with both CAD and PAD ${ }^{9}$. Dysbetalipoproteinemia is characterized by the accumulation of remnants of chylomicrons and very lowdensity lipoprotein (VLDL), which contain more triglycerides and are larger than LDL. Patients with diabetes mellitus sometimes exhibit increased levels of remnant lipoproteins ${ }^{10)}$ and high prevalence of PAD. Although patients with lipoprotein lipase deficiency exhibit large amounts of chylomicrons and VLDL, atherosclerosis does not seem to develop at an accelerated rate. Therefore, it is possible that the characteris-

Address for correspondence: Mariko Harada-Shiba, Department of Molecular Innovation in Lipidology, National Cerebral and Cardiovascular Center Research Institute, 6-1 Kishibeshinmachi, Suita, Osaka, 564-8565 JapanＥ-mail: mshiba@ncvc.go.jp

Received: October 1, 2019 Accepted for publication: October 2, 2019

Copyright@2019 Japan Atherosclerosis Society

This article is distributed under the terms of the latest version of CC BY-NC-SA defined by the Creative Commons Attribution License. 
tics of increased lipoproteins are associated with the differences in the extent of atherosclerosis development in certain arteries. Patients with $\mathrm{FH}$ are mainly characterized by very high LDL-C levels, but remnant lipoprotein cholesterol (RLP-C) levels have also been reported to be high ${ }^{11)}$ and to be associated with $\mathrm{CAD}^{12)}$. PAD in patients with $\mathrm{FH}$ may be partially related to high RLP-C levels. Akioyamen et al. ${ }^{13)}$ reported in a meta-analysis that $\mathrm{FH}$ was associated with a high risk of PAD; however, this trend was not preserved in molecularly defined $\mathrm{FH}$.

Large arteries are prone to be affected by lipid accumulation with proliferative changes, leading to plaque formation ${ }^{14)}$. Arteriosclerosis in small arteries like cerebral penetrating arteries is characterized by the necrosis or apoptosis of smooth muscle cells, resulting in lacunar stroke ${ }^{14)}$. In the present paper, although the large arteries were not affected, small arteries were found to be affected. It should be noted that this study was performed in the Tohoku area, where the prevalence of hypertension is higher than that in other parts of Japan, and that the mean systolic blood pressure in patients with $\mathrm{FH}$ is higher than that in control subjects. In addition, the number of patients in the study group is small. Therefore, the results of the present study may be affected by blood pressure or some other factors. Further study with a larger number of patients needs to be performed.

\section{Conflicts of Interests}

Dr. Harada-Shiba reports honoraria from Astellas Pharma, Astellas Amgen and Sanofi, grants from Aegerion, Ricordati, Astellas, Astellas Amgen and Kaneka Medics, stock ownership of Liid Pharm, outside the submitted work.

\section{References}

1) Harada-Shiba $M$, Arai H, Ishigaki $Y$, Ishibashi $S$, Okamura T, Ogura M, Dobashi K, Nohara A, Bujo H, Miyauchi K, Yamashita S, Yokote K. Guidelines for diagnosis and treatment of familial hypercholesterolemia 2017. J Atheroscler Thromb, 2018; 25: 751-770

2) Harada-Shiba M, Ohta T, Ohtake A, Ogura M, Dobashi K, Nohara A, Yamashita S, Yokote K. Guidance for pediatric familial hypercholesterolemia 2017. J Atheroscler Thromb, 2018; 25: 539-553
3) Kaste M, Koivisto P. Risk of brain infarction in familial hypercholesterolemia. Stroke, 1988; 19: 1097-1100

4) Gagne C, Moorjani S, Brun D, Toussaint M, Lupien PJ. Heterozygous familial hypercholesterolemia. Relationship between plasma lipids, lipoproteins, clinical manifestations and ischaemic heart disease in men and women. Atherosclerosis, 1979; 34: 13-24

5) Barkas F, Elisaf M, Milionis H. Statins decrease the risk of stroke in individuals with heterozygous familial hypercholesterolemia: A systematic review and meta-analysis. Atherosclerosis, 2015; 243: 60-64

6) Todate Y, Uwano I, Yashiro S, Chida A, Hasegawa Y, Oda T, Nagasawa K, Honma H, Sasaki M, Ishigaki Y. High prevalence of cerebral small vessel disease on $7 \mathrm{t}$ magnetic resonance imaging in familial hypercholesterolemia. J Atheroscler Thromb, 2019; 26: 1045-1053

7) Tendera M, Aboyans V, Bartelink ML, Baumgartner I, Clement D, Collet JP, Cremonesi A, De Carlo M, Erbel R, Fowkes FG, Heras M, Kownator S, Minar E, Ostergren J, Poldermans D, Riambau V, Roffi M, Rother J, Sievert H, van Sambeek M, Zeller T. Esc guidelines on the diagnosis and treatment of peripheral artery diseases: Document covering atherosclerotic disease of extracranial carotid and vertebral, mesenteric, renal, upper and lower extremity arteries: The task force on the diagnosis and treatment of peripheral artery diseases of the european society of cardiology (esc). Eur Heart J, 2011; 32: 28512906

8) Jashari F, Ibrahimi P, Nicoll R, Bajraktari G, Wester P, Henein MY. Coronary and carotid atherosclerosis: Similarities and differences. Atherosclerosis, 2013; 227: 193200

9) Marais AD, Solomon GA, Blom DJ. Dysbetalipoproteinaemia: A mixed hyperlipidaemia of remnant lipoproteins due to mutations in apolipoprotein e. Crit Rev Clin Lab Sci, 2014; 51: 46-62

10) Soran H, Schofield JD, Adam S, Durrington PN. Diabetic dyslipidaemia. Curr Opin Lipidol, 2016; 27: 313322

11) Miller PE, Martin SS, Toth PP, Santos RD, Blaha MJ, Nasir K, Virani SS, Post WS, Blumenthal RS, Jones SR. Screening and advanced lipid phenotyping in familial hypercholesterolemia: The very large database of lipids study-17 (vldl-17). J Clin Lipidol, 2015; 9: 676-683

12) Tada H, Kawashiri MA, Nohara A, Sakata K, Inazu A, Mabuchi H, Yamagishi M, Hayashi K. Remnant-like particles and coronary artery disease in familial hypercholesterolemia. Clin Chim Acta, 2018; 482: 120-123

13) Akioyamen LE, Tu JV, Genest J, Ko DT, Coutin AJS, Shan SD, Chu A. Risk of ischemic stroke and peripheral arterial disease in heterozygous familial hypercholesterolemia: A meta-analysis. Angiology, 2019; 70: 726-736

14) Iso H. Lifestyle and cardiovascular disease in japan. J Atheroscler Thromb, 2011; 18: 83-88 